\title{
EL CIEGO DE LA GUITARRA FRANCISCO DE GOYA Y LUCIENTES [Fuendetodos (Zaragoza), 1746 - Burdeos (Francia), 1828]
}

\author{
NOGUERA-PALÁU JJ ${ }^{1}$
}

Los tapices, paños grandes tejidos con lana o seda, y algunas veces con oro y plata, en los que se copian cuadros y sirven de paramento, según la definición de la Real Academia Española, tienen sus primeras muestras allá por el siglo XV a.C. en el mundo de los egipcios. Para este artículo de hoy tendremos que adelantarnos unos 31000 años hasta llegar a los creados a partir de pinturas de Goya.

Para la confección de los tapices se partía de un cartón, que no era sino un boceto o un lienzo más o menos finamente elaborado que servía de modelo para su adecuada reproducción en colores y tamaño. Se tejían en telares verticales, llamados de alto lizo, u horizontales, de bajo lizo; en estos el cartón se colocaba bajo la urdimbre y el tejedor trabajaba en el anverso del tapiz, y en los verticales se veía el cartón, dispuesto detrás del tejedor, reflejado en un espejo detrás del telar y se trabajaba en el reverso del tapiz.

En Madrid, entre los siglos XVI y XVIII se instalaron varias manufacturas de tapices. En 1591, durante el reinado de Felipe II, se creó un taller de tapices en la calle de Santa Isabel; se ha querido ver en el cuadro Las hilanderas (1657) de Velázquez, opinión discutida si no rechazada, una imagen de aquella casa de tapices. En 1720, en la conocida como casa de El Abreviador, entonces almacén de pólvora, cerca de la puerta de Santa Bárbara, en la confluencia de las actuales calles de Sagasta y Santa Engracia con la plaza de Alonso Martínez, se creó la Casa de tapices de Santa Bárbara para cumplir con los encargos de Felipe V; en este taller, con tapiceros venidos de Amberes y dirigidos por Jacobo Vandergoten «el Viejo», se instalaron unos telares de bajo lizo. En 1734, donde había estado la antigua manufactura de tapices de la calle de Santa Isabel, se montaron unos telares de alto lizo con personal venido del taller de la Lonja de Sevilla y a las órdenes de Jacobo Vandergoten «el Joven». En 1744, por cuestiones económicas, ambas casas se unieron en las dependencias de la de Santa Bárbara convirtiéndose en la Real Fábrica de Tapices al pasar a depender de la Corona. Para esta nueva manufactura, bajo la dirección de Cornelio Vandergoten, Goya pintó sesenta y tres cartones entre 1775 y 1793 , con un periodo de descanso entre 1780 y 1786; los cartones se conservan en el Museo del Prado y en colecciones particulares, y los tapices que se tejieron con estos cartones se destinaron a los palacios reales de El Escorial y El Pardo en tiempos de Carlos III y Carlos IV.

El sello de hoy ilustra el tapiz elaborado en seda y lana de El ciego de la guitarra, perteneciente a una colección de trece piezas destinadas a decorar las antesalas del dormitorio de Carlos de Borbón y María Luisa de Parma en el palacio de El Pardo. Procede del cartón realizado en óleo sobre lienzo $(260$ x $311 \mathrm{~cm})$ en 1778 y conservado en el Museo del Prado. Éste fue el segundo cartón que Goya entregó al taller de Santa Bárbara para la confección del tapiz; el primero le fue devuelto a los seis

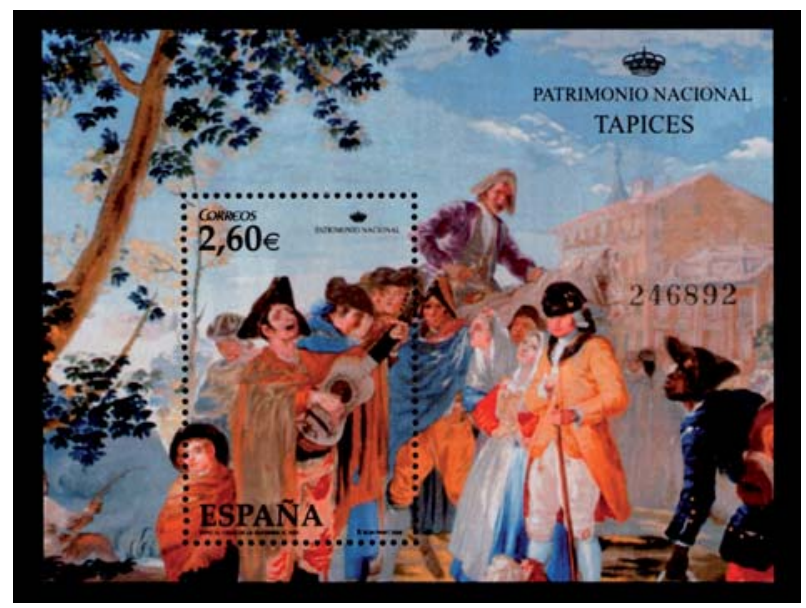

España, 2008 - Yvert 4049 (HB 169) de 4048/49 (HB 168/69).

\footnotetext{
1 Oftalmólogo. Pamplona.

E-mail: jnoguera72b@terra.es
} 


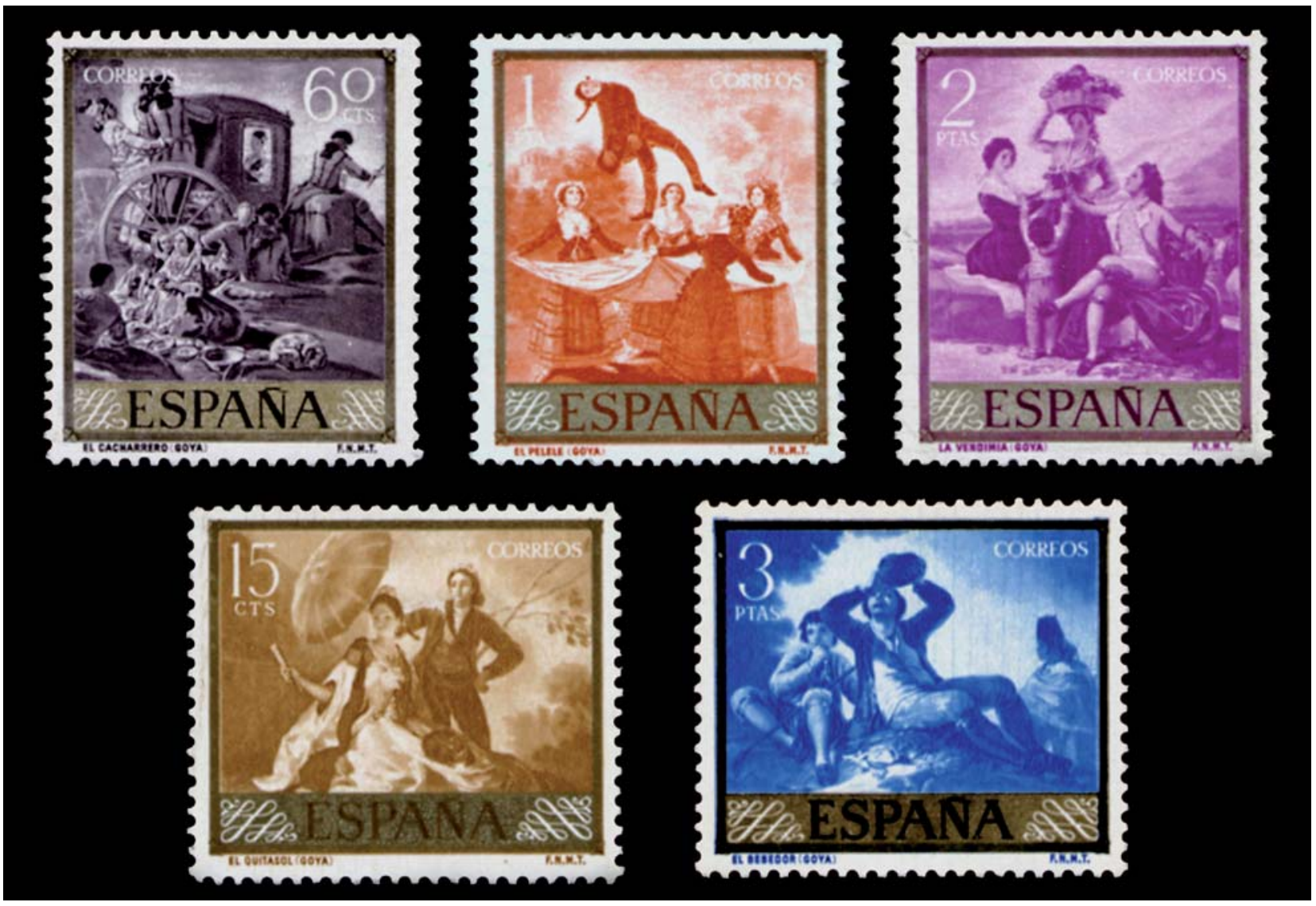

En la emisión española del 24 de marzo de 1958, Día del Sello, dedicada a Goya (Edifil 1210/19), se reprodujeron otros de sus cartones: El cacharrero, El pelele, La vendimia o el otoño, El quitasol y El bebedor.

meses de haberlo presentado con la exigencia de modificarlo por la dificultad que entrañaba su reproducción. Goya redujo el tamaño del primer cartón y suprimió algunas figuras. La escena, según el director del taller de Santa Bárbara, se sitúa en la plaza de la Cebada de Madrid. 